\title{
Lengthening With External Fixation Is Effective in Congenital Femoral Deficiency
}

\author{
Daniel E. Prince MD, MPH, John E. Herzenberg MD, Shawn C. Standard MD, \\ Dror Paley MD
}

Received: 12 February 2015/Accepted: 8 July 2015/Published online: 21 July 2015

(C) The Association of Bone and Joint Surgeons \& 2015

\begin{abstract}
Background Treatment of congenital femoral deficiency is a complex, multistage protocol and a variety of strategies have been devised to address joint instability, limb length inequality, and deformities. Despite being an important part of the algorithmic approach to the overall treatment of patients with congenital femoral deficiency, a reproducible, safe, and functional treatment for femoral length discrepancy in patients with mild and moderate congenital femoral deficiency has not been reported.

Questions/purposes (1) Does femoral lengthening by means of distraction osteogenesis, using a monolateral external fixator, result in effective lengthening without loss
\end{abstract}

One or more of the authors (DEP) received less than USD 10,000 from Smith \& Nephew (Memphis, TN, USA) outside of this work. One or more of the authors (SCS) received personal fees from Pega Medical (Laval, Quebec, Canada) and Ellipse Technologies (Irvine, CA, USA) outside the submitted work and the following companies supported his institution's annual course for orthopaedic surgeons: Smith \& Nephew, Ellipse Technologies, Stryker (Mahwah, NJ, USA), Brainlab (Munich, Bavaria, Germany), DePuy Synthes (Warsaw, IN, USA), Orthofix International (Lewisville, TX, USA), Biomet (Warsaw, IN, USA), KCI (San Antonio, TX, USA), OrthoPediatrics (Warsaw, IN, USA), OHK Medical Devices (Haifa, Israel), and The Multiple Hereditary Exostosis Coalition (Parma Heights, OH, USA). The following companies supported his institution's nonprofit organization, which provides financial assistance to our patients: Stryker, Orthocare Solutions (Rockville, MD, USA), and Metro Prosthetics (Baltimore, MD, USA). One or more of the authors (JEH) received grants from OrthoPediatrics and Ellipse Technologies outside the submitted work and the following companies supported his institution's annual course for orthopaedic surgeons: Smith \& Nephew, Ellipse Technologies, Stryker, Brainlab, DePuy Synthes, Orthofix, Biomet, KCI, OrthoPediatrics, OHK Medical Devices, and The MHE Coalition. The following companies supported his institution's nonprofit organization, which provides financial assistance to our patients: Stryker, Orthocare Solutions, and Metro Prosthetics. One or more of the authors (DP) received personal fees from Smith \& Nephew, Ellipse Technologies, 3D Concepts of hip or knee range of motion? (2) Does femoral lengthening cause an inhibition of femoral growth in patients with congenital femoral deficiency? (3) Do patients/families report satisfactory functional and emotional outcomes after undergoing femoral lengthening? (4) What proportion of patients develops complications after femoral lengthening with this technique?

Methods Between 2005 and 2009, we evaluated 38 patients for femoral length discrepancy secondary to unilateral congenital femoral deficiency. Thirty-two patients completed treatment with distraction osteogenesis using a monolateral external fixator; general indications for this approach were congenital femoral deficiency Paley Types

(Schaumburg, IL, USA), Pega Medical, and Springer (New York, NY, USA) outside the submitted work. The institution of one or more of the authors (JEH, SCS, DP) has received, during the study period, funding from Smith \& Nephew, DePuy Synthes, Orthofix, Biomet, and OrthoPediatrics. One or more of the authors certifies that he (SCS), or a member of his or her immediate family, has received or may receive payments or benefits, during the study period, an amount less than USD 10,000 from Smith \& Nephew, an amount less than USD 10,000 from Ellipse Technologies, and an amount less than USD 10,000 from Orthofix. One or more of the authors certifies that he (DP), or a member of his or her immediate family, has received or may receive payments or benefits, during the study period, an amount of USD 100,001 to USD $1,000,000$ from Orthofix, Inc during the period of this study. All ICMJE Conflict of Interest Forms for authors and Clinical Orthopaedics and Related Research ${ }^{\circledR}$ editors and board members are on file with the publication and can be viewed on request.

Clinical Orthopaedics and Related Research ${ }^{\mathbb{R}}$ neither advocates nor endorses the use of any treatment, drug, or device. Readers are encouraged to always seek additional information, including FDA approval status, of any drug or device before clinical use. Each author certifies that his or her institution approved the human protocol for this investigation, that all investigations were conducted in conformity with ethical principles of research, and that informed consent for participation in the study was obtained. 
$1 \mathrm{a}, 1 \mathrm{~b}$, or $2 \mathrm{a}$ that had not previously undergone lengthening and had stable hip and knee joints. Of the 32 patients that completed treatment, $30(94 \%)$ were available at a minimum of 2 years (mean, 3 years; range, 2-4.5 years) and were evaluated in this retrospective study. Preoperative and postoperative radiographic analysis, physiotherapy data, patient-based outcomes scores, and complications were reviewed for all eligible patients. Growth inhibition was measured using serial radiographs over the 2-year followup with the unaffected limb considered the norm. Functional and emotional outcomes were reported by adolescent patients or parents of younger children using the Pediatric Orthopaedic Society of North America Pediatric Outcomes Data Collection Instruments (PODCI), a validated patientbased outcomes measure.

Results The mean distal femoral lengthening was $6 \mathrm{~cm}$ (SD $\pm 2 \mathrm{~cm}$; range, $1.6-9 \mathrm{~cm}$ ), for a mean percent of femoral length discrepancy correction of $112 \%$ (SD \pm $55 \%$; range, $15 \%-215 \%$ ). Comparison of patient preoperative with postoperative mean hip and knee flexion and extension showed no difference with the numbers available (hip flexion: $p=0.219$, mean difference of $-5,95 \%$ confidence interval $[\mathrm{CI}], 10, \mathrm{SD}=20$; hip extension: $\mathrm{p}=0.423$, mean difference of $-1,95 \% \mathrm{CI}, 2, \mathrm{SD}=5$; knee flexion: mean difference of $-7^{\circ}, \mathrm{SD} \pm 29^{\circ}, \mathrm{CI}, 15, \mathrm{p}=0.467$; knee extension: mean difference of $-1^{\circ}, \mathrm{SD} \pm 9^{\circ}, \mathrm{CI}, 4, \mathrm{p}=$ 0.757). A comparison of the mean preoperative inhibition of $41 \%$ (range, $-38 \%$ to $300 \%$; $\mathrm{SD} \pm 72 ; 95 \% \mathrm{CI}, 29 \%$ ) with the mean postoperative inhibition of $16 \%$ (range, $-242 \%$ to $100 \%$; SD $\pm 61 \%$; $95 \%$ CI, $25 \%$ ) for a mean postoperative stimulation of $25 \%$ ( $\mathrm{p}=0.055, \mathrm{SD} \pm 90 \%$; 95\% CI, 36\%). In all six PODCI categories surveyed, patients had favorable standardized and normative scores, but patients who underwent femoral lengthening greater than $6 \mathrm{~cm}$ had both lower global functioning scores (90, SD \pm 10 versus $96, \mathrm{SD} \pm 3, \mathrm{p}=0.043)$ and worse pain/comfort scores (79, $\mathrm{SD} \pm 25$ versus $96, \mathrm{SD} \pm 7, \mathrm{p}=0.029)$, and patients who had mean percent femoral lengthening greater

This work was performed at the International Center for Limb Lengthening of the Rubin Institute for Advanced Orthopaedics at Sinai Hospital of Baltimore, Baltimore, MD, USA.

D. E. Prince $(\square)$

Memorial Sloan Kettering Cancer Center, 1275 York Avenue,

Howard 1013, New York, NY 10065, USA

e-mail: PrinceD@mskcc.org

J. E. Herzenberg, S. C. Standard

International Center for Limb Lengthening, Rubin Institute

for Advanced Orthopaedics, Sinai Hospital of Baltimore,

Baltimore, MD, USA

D. Paley

Paley Advanced Limb Lengthening Institute, West Palm Beach, FL, USA than $25 \%$ of initial femur length had worse pain/comfort scores $(79, \mathrm{SD} \pm 23$ versus $97, \mathrm{SD} \pm 4, \mathrm{p}=0.012)$ with similar global functioning scores $(90, \mathrm{SD} \pm 9$ versus 96 , $\mathrm{SD} \pm 3, \mathrm{p}=0.058)$. The total number of postsurgical complications was 30 in 60 planned surgical procedures $(50 \%)$.

Conclusions Our study results support the use of the described surgical technique for femoral lengthening in treating patients with congenital femoral deficiency. Additional studies are needed both to follow long-term patient-reported outcome measures, especially after a second or third lengthening, and to determine the effect of serial lengthening on the stimulation or inhibition of growth and rate of complications.

Level of Evidence Level IV, therapeutic study.

\section{Introduction}

Congenital femoral deficiency was first described by Aitken as a varied array of congenital deformities affecting the lower limb, centered on the proximal femur, but distinct from isolated coxa vara [2]. Deformities of the limb vary from a normal but shortened femur in very mild cases, to severe coxa vara, a pseudoarthrosis of the proximal femur, distal femoral valgus, aplasia or hypoplasia of the ligaments, hypoplasia of the musculature, and aberrant vasculature $[2,3,8,10,15,19,43]$.

Treatment for patients with mild congenital femoral deficiency (Paley Type 1a and 1b) generally has involved lengthening of the shortened extremity, whereas treatment for patients with moderate congenital femoral deficiency (Paley Type 2a) has been knee fusion and prosthetic fitting, rotationplasty, Syme amputation, or ablative treatment [1, $11,13,15,20,41,44,46]$. Recently, advances in treating moderate congenital femoral deficiency by lengthening have allowed preservation of a functional limb while attempting to lessen the psychosocial burden on the patient [4, 31]. Although femoral lengthening for congenital femoral deficiency has been described using a variety of techniques [4, 31], to our knowledge, no data on the amount of length gained, ROM of the hip and knee, femoral growth inhibition or stimulation, patient-reported outcome scores, or specific complications have been reported using a single consistent technique. Inhibition of growth of the affected femur in congenital femoral deficiency is well known [3, 8] as is the stimulation of growth after femur fracture [5, 7, 12, 18, 23, 37, 40, 42]; however, the effect of limb lengthening on bone growth is controversial [17, 34, 38, 45]. Lengthening surgery exerts tension on the soft tissues and pressure on the adjacent physis that may result in growth inhibition [25, 26]. A safe and reproducible surgical technique for femoral lengthening 
has not been established for treating femoral length discrepancy in patients with congenital femoral deficiency nor have patient-based outcomes been correlated to clinical outcomes to assess resultant patient function and psychosocial effects of the lengthy and intense surgical treatment and recovery.

We therefore asked: (1) Does femoral lengthening by means of distraction osteogenesis using a monolateral external fixator followed by internal rodding result in effective lengthening without loss of hip or knee ROM in patients with congenital femoral deficiency? (2) Does femoral lengthening cause an inhibition of femoral growth in patients with congenital femoral deficiency? (3) Do patients/families report satisfactory functional and emotional outcomes after undergoing femoral lengthening with an external fixator? (4) What proportion of patients develops complications after femoral lengthening with this technique?

\section{Patients and Methods}

Between 2005 and 2009, 38 patients were evaluated for unilateral Paley Type 1a, 1b, and 2a unilateral congenital femoral deficiency. Of the 38 patients, 33 patients with femoral length discrepancy were treated with distraction osteogenesis using a monolateral external fixator; general indications for this approach were stable hips and knees and no prior femoral lengthening (Table 1). Patients with bilateral congenital femoral deficiency were excluded from our study because predicted overall limb length discrepancy and growth inhibition are calculated based on a normal contralateral leg and recovery may be impaired with bilateral involvement. Six patients who were treated with unilateral congenital femoral deficiency were not included in the current study because two did not undergo femoral lengthening during the specified timeframe, one had a previous lengthening at another institution, two did not receive the described standard surgical technique because they had concurrent tibial lengthening, and one patient did not complete the treatment during the specified timeframe. Of the 32 patients who underwent the surgery and met the other eligibility criteria, 30 (94\%) were available at a minimum of 2 years (mean, 3 years; range, $2-4.5$ years) and were evaluated in this retrospective study; two patients were excluded because of insufficient radiographic data. All procedures were performed by two surgeons (SCS, DP) using the same technique at the same institution with standardized postoperative care, physical therapy, and followup schedule. Patient charts and radiographs were reviewed by an orthopaedic surgeon with fellowship training in limb lengthening and deformity correction (DEP) for demographic data, radiographic measurements, surgical complications, resultant ROM, and rates of all problems, obstacles, and complications [27].

All patients underwent the same surgical technique using the adult-sized rail in larger patients and the pediatric-sized rail in smaller patients [31]. The major aspects of the uniform surgical technique used included a distal femoral osteotomy for distraction osteogenesis; a monolateral rail with multiaxial half pins in each segment (Orthofix Limb Reconstructive System [LRS]; Orthofix International NV, Lewisville, TX, USA); a hinged external fixation construct across the knee; a mean distraction rate of $1 \mathrm{~mm}$ per day; and Rush rodding (Rush Pin LLC, Meridian, MS, USA) of the femur at the time of external fixation removal. Osteotomy was performed percutaneously through a $1-\mathrm{cm}$ anterolateral incision at the distal metaphysis just proximal to the three distal pins via the multiple drill hole technique with a 4-mm drill in smaller femurs and a 5-mm drill in larger femurs and completed with an osteotome. If the hip was considered at risk for subluxation before lengthening, the pelvis was spanned with an additional hinged construct [31]. The Orthofix LRS is FDA-approved for use in children and adults.

Patient aftercare included physical therapy performed for 1 hour five times per week to maintain a minimum of $45^{\circ}$ of flexion and full extension throughout the lengthening phase. Additionally, an extension bar across the knee hinge to maintain full knee extension was used at night. If a decrease in knee flexion or tibiofemoral subluxation became a concern, the rate of lengthening was either slowed or stopped and the intensity of physical therapy increased to 2 hours per day five times per week until either ROM was restored to acceptable limits or the decision was made to stop lengthening. Additionally, parents were taught and encouraged to perform a limited therapy protocol on weekends.

Followup consisted of patient office visits with radiographs taken every 2 weeks during the lengthening phase followed by monthly visits with radiographs during consolidation. After consolidation, followup radiographs were obtained every 6 months. The daily pin care recommendation of the institution at the time of the study was "attentive but not aggressive"; the recommendation was daily showering with gentle cleansing of the pin sites with a soft washcloth and antibacterial soap and once the pin sites were dried, the pins were wrapped with gauze or marshmallow sponges to prevent motion at the pin-skin interface.

Complications are reported as problems, obstacles, minor complications, and major complications [27]. Problems are defined as difficulties that do not interfere with the course of treatment and do not require operative intervention to resolve; obstacles require operative intervention but do not interfere with the course of treatment; complications 
Table 1. Patient demographics

\begin{tabular}{|c|c|c|}
\hline \multicolumn{2}{|c|}{ Preoperative characteristics } & $\begin{array}{l}\text { Number of patients } \\
\text { (percentage) } \mathrm{N}=30\end{array}$ \\
\hline \multicolumn{3}{|l|}{ Gender } \\
\hline \multicolumn{2}{|l|}{ Male } & $15(50 \%)$ \\
\hline \multicolumn{2}{|l|}{ Female } & $15(50 \%)$ \\
\hline \multicolumn{3}{|c|}{ Congenital femoral deficiency type } \\
\hline \multicolumn{2}{|l|}{ Paley 1A } & $18(60 \%)$ \\
\hline \multicolumn{2}{|l|}{ Paley 1B } & $9(30 \%)$ \\
\hline \multicolumn{2}{|l|}{ Paley 2A } & $3(10 \%)$ \\
\hline \multicolumn{2}{|c|}{$\begin{array}{l}\text { Age at first femoral lengthening } \\
\text { (years; range) }\end{array}$} & $4.5(2-11)$ \\
\hline \multirow{4}{*}{\multicolumn{2}{|c|}{ Additional diagnoses }} & 4 fibular hemimelia \\
\hline & & 2 tibial hemimelia \\
\hline & & $\begin{array}{l}1 \text { multiple hereditary } \\
\text { exostosis }\end{array}$ \\
\hline & & 1 toe syndactyly \\
\hline \multicolumn{3}{|l|}{ Prior surgeries } \\
\hline \multicolumn{2}{|l|}{ SUPERhip } & $24(80 \%)$ \\
\hline \multicolumn{2}{|l|}{ SUPERknee } & $15 / 24(63 \%)$ \\
\hline \multicolumn{2}{|c|}{ Femoral neck bone grafting } & $5(16 \%)$ \\
\hline \multicolumn{2}{|c|}{ Foot/ankle reconstruction } & $3(10 \%)$ \\
\hline \multicolumn{2}{|c|}{ Débridement and wound closure } & $1(3 \%)$ \\
\hline \multicolumn{2}{|c|}{ Removal of hardware } & $1(3 \%)$ \\
\hline \multicolumn{2}{|c|}{ Spanning external fixation } & $1(3 \%)$ \\
\hline \multicolumn{2}{|c|}{ Sciatic nerve decompression } & $1(3 \%)$ \\
\hline \multicolumn{2}{|l|}{ Quadricepsplasty } & $1(3 \%)$ \\
\hline \multicolumn{2}{|l|}{ Tibial lengthening } & $1(3 \%)$ \\
\hline \multicolumn{2}{|c|}{ Toe syndactyly release } & $1(3 \%)$ \\
\hline \multicolumn{2}{|c|}{ Calcaneal osteotomy } & $1(3 \%)$ \\
\hline Baseline ROM & Hip & Knee \\
\hline Flexion (range) & $121^{\circ}\left(90^{\circ}-130^{\circ}\right)$ & $130^{\circ}\left(105^{\circ}-140^{\circ}\right)$ \\
\hline Extension (range) & $0.5^{\circ}\left(-5^{\circ}\right.$ to $\left.0^{\circ}\right)$ & $2^{\circ}\left(0^{\circ}-20^{\circ}\right)$ \\
\hline
\end{tabular}

require operative intervention to resolve, prolong treatment, and are considered major if they result in a permanent residual deficit. The proportion of problems such as minor pin tract infections, external fixation modifications not requiring surgical intervention, and stiffness that responded to physical therapy were not regularly recorded by practitioners at followup or therapy visits and therefore could not accurately be assessed.

For all patients, radiographic data were obtained from both digital and traditional films with a magnification marker in all instances measuring overall limb length discrepancy, femur and tibial lengths, mechanical lateral distal femur angle, and mechanical axis deviation. Using formulae derived from the multiplier method described by Paley et al., predicted developmental and congenital femoral length discrepancy, predicted congenital overall limb length discrepancy, and growth stimulation or inhibition were calculated [28-33]. The congenital method of predicted limb length discrepancy uses the inhibition to predict future growth, whereas the developmental method uses radiographs at two known time points to predict growth at a future time point. Growth inhibition or stimulation is calculated using serial radiographs at different time points measuring the amount of growth in the affected femur compared with the amount of growth in the unaffected, normal femur and the difference in rate of growth is calculated as a percentage of normal growth. Growth inhibition implies less growth than the normal side, whereas growth stimulation implies greater growth than the normal side. Because the concept was initially defined as growth inhibition, a positive score indicates inhibition of the affected femur, whereas a negative percentage indicates stimulation of the affected femur. In this study growth inhibition or stimulation was calculated beginning at removal of the external fixator and ending 2 years after removal. All patients underwent physical therapy at the same facility, including an initial preoperative assessment. Measurements were recorded by the physical therapist at each therapy visit.

Patient-based outcome scores were obtained using the Pediatric Orthopaedic Society of North America Pediatric Outcomes Data Collection Instruments (PODCI), a validated patient-based outcomes measure [6, 14]. Standardized scores for PODCI are calculated so that " 0 " represents a poor outcome/worse health and "100" is the best possible outcome/best health. Normative scores are calculated so that higher scores indicate better functioning referenced to the general/healthy population mean score of 50. The PODCI includes scales for upper extremity, basic mobility, sports and physical functioning, pain/comfort, happiness, and global function. PODCI scores were obtained at a minimum of 2 years after completing lengthening between 2010 and 2011 by dedicated research coordinators at routine followup visits, by mail or phone, using the validated PODCI age-appropriate questionnaires for adolescents and parent questionnaires for younger children. The PODCI was not collected in five patients who had subsequently undergone a second lengthening or other major surgical intervention and two patients who did not respond to the requests. All children had access to a child life specialist employed by the practice for emotional support during the lengthening treatment.

Statistical analysis was conducted using SPSS Statistics 22.0 (IBM North America, New York, NY, USA) with paired t-tests for preoperative and postoperative comparisons and multivariate analysis of variables assuming independence of observations, normal distribution, and homoscedasticity with significance determined at $\mathrm{p}$ values $<0.05$.

The average age at the time of femoral lengthening was 4.5 years (range, $2-11$ years), which was 17 months (range, 
5-55 months) after a SUPERhip stabilization procedure in 24 patients (Table 1 ). Fifteen of the 24 patients underwent a concomitant SUPERknee at the time of SUPERhip surgery. The SUPERhip and SUPERknee procedures are combination surgeries to realign the osseous structures, reconstruct atrophied or missing ligamentous structures, and redirect muscle tension to achieve and maintain hip and knee stability and ROM, respectively [31]. Twelve patients $(40 \%)$ underwent surgeries prior to the femoral lengthening aside from a SUPERhip or SUPERknee procedure. In eight patients the previous surgeries were related to prior hip stabilization: three patients required femoral neck bone grafting, one required débridement and primary closure of a hip wound dehiscence, one required removal of hardware from the hip, one required a spanning external fixator for hip instability and femoral neck bone grafting twice, one required a sciatic nerve decompression, and one required a quadricepsplasty and femoral neck bone grafting. Four patients required procedures related to foot and ankle deformity: three required ankle and foot reconstruction with an external fixator, one of which also required tibial lengthening with external fixation, and one required both toe syndactyly release and a calcaneal osteotomy. No difference was found preoperatively in predicting the femoral length discrepancy using the congenital formula and the developmental formula with the numbers available $(12 \mathrm{~cm} \pm 6 \mathrm{SD}$; range, $3-24 \mathrm{~cm}$ versus $16 \mathrm{~cm} \pm 19 \mathrm{SD}$; range, 2-91 cm; $\mathrm{p}=0.309$; Table 2). Preoperative growth inhibition of the affected femur compared with the contralateral normal femur was calculated at $41 \%$ ( $\pm \mathrm{SD} 72 \%$; range, $-38 \%$ to $300 \%$; $95 \%$ confidence interval [CI], $\pm 29 \%$ ). Four patients had femoral growth stimulation preoperatively and although two were quite minor $(2.8 \%$ and $2.7 \%)$, the other two patients experienced significant growth stimulation of $38 \%$ and $23 \%$. All four patients with preoperative stimulation underwent a SUPERhip procedure. The patient with $38 \%$ stimulation had previously required bone grafting of the femoral neck twice after a combined SUPERhip and SUPERknee procedure, although the other patient with significant stimulation did not undergo bone grafting or other intervention.

The goal of lengthening surgery is a temporary equalization of overall limb length and with the expectation of lengthening attaining at least $5 \mathrm{~cm}$ and rarely more than $7.5 \mathrm{~cm}$, this determines partly when lengthening surgery is

Table 2. Radiographic measurements and predictive calculations of length discrepancy

\begin{tabular}{|c|c|c|c|c|c|c|c|c|}
\hline \multirow[b]{2}{*}{ Measured value } & \multicolumn{2}{|l|}{ Preoperative } & \multicolumn{3}{|c|}{ After lengthening } & \multicolumn{3}{|l|}{ Followup } \\
\hline & Mean \pm SD & Range $\pm 95 \% \mathrm{CI}$ & Mean \pm SD & Range $\pm 95 \%$ CI & $\mathrm{p}$ value ${ }^{*}$ & Mean \pm SD & Range $\pm 95 \%$ CI & $\mathrm{p}$ value $^{\dagger}$ \\
\hline $\begin{array}{l}\text { Overall limb length } \\
\text { discrepancy }(\mathrm{cm})\end{array}$ & $7.0 \pm 3$ & 4 to $16 \pm 1$ & $1.5 \pm 1$ & -4 to $6 \pm 0.1$ & $<0.001$ & $3 \pm 3$ & 0 to $11 \pm 12$ & $<0.001$ \\
\hline $\begin{array}{l}\text { Femoral length } \\
\text { discrepancy }(\mathrm{cm})\end{array}$ & $6.7 \pm 4$ & 2 to $15 \pm 1$ & $2 \pm 0.3$ & -3 to $9 \pm 0.3$ & $<0.001$ & $23 \pm 4$ & -3 to $9 \pm 2$ & 0.025 \\
\hline $\begin{array}{l}\text { Mechanical axis } \\
\text { deviation }(\mathrm{mm})\end{array}$ & 9 lat \pm 14 & $\begin{array}{r}40 \text { lat to } 15 \\
\text { med } \pm 6\end{array}$ & 1 lat \pm 3 & $\begin{array}{l}20 \text { lat to } 22 \\
\text { med } \pm 0.1\end{array}$ & 0.028 & 17 lat \pm 12 & $\begin{array}{l}41 \text { lat to } 6 \\
\text { med } \pm 5\end{array}$ & $<0.001$ \\
\hline mLDFA (degrees) & $87 \pm 4$ & 79 to $94 \pm 2$ & $92 \pm 0.5$ & 82 to $104 \pm 2$ & $<0.001$ & $87 \pm 3$ & 81 to $95 \pm 1$ & $<0.001$ \\
\hline \multicolumn{9}{|l|}{$\begin{array}{l}\text { Predicted overall limb } \\
\text { length discrepancy }\end{array}$} \\
\hline $\begin{array}{l}\text { Congenital } \\
\text { method }(\mathrm{cm})\end{array}$ & $13 \pm 5$ & 6 to $25 \pm 18$ & $4.0 \pm 0.2$ & 0 to $18 \pm 2$ & $<0.001$ & $5 \pm 4$ & 0 to $18 \pm 2$ & 0.010 \\
\hline \multicolumn{9}{|l|}{$\begin{array}{l}\text { Predicted femoral } \\
\text { length discrepancy }\end{array}$} \\
\hline $\begin{array}{l}\text { Congenital } \\
\text { method }(\mathrm{cm})\end{array}$ & $12 \pm 6$ & 3 to $24 \pm 2$ & $5 \pm 0.7$ & 0 to $18 \pm 2$ & $<0.001$ & $6 \pm 4$ & 0 to $14 \pm 2$ & 0.101 \\
\hline $\begin{array}{l}\text { Developmental } \\
\text { method }(\mathrm{cm})\end{array}$ & & & & & $0.237^{*}$ & & & $0.124^{\S}$ \\
\hline $\begin{array}{l}\text { Preoperative } \\
\text { inhibition }\end{array}$ & $16 \pm 19$ & 2 to $91 \pm 8$ & $10.5 \pm 7$ & -3 to $77 \pm 7$ & $<0.001$ & $11 \pm 17$ & -3 to $78 \pm 7$ & 0.025 \\
\hline $\begin{array}{l}\text { Postoperative } \\
\text { inhibition }\end{array}$ & & & $7 \pm 0.1$ & -9 to $15 \pm 3$ & & $5 \pm 14$ & -6 to $19 \pm 6$ & $<0.001$ \\
\hline $\begin{array}{l}\text { Growth } \\
\quad \text { inhibition (\%) }\end{array}$ & $41 \pm 72$ & -38 to $300 \pm 29$ & & & & $16 \pm 61$ & -242 to $100 \pm 25$ & 0.055 \\
\hline
\end{tabular}

$* \mathrm{p}$ value comparing preoperative and after lengthening means; ${ }^{\dagger} \mathrm{p}$ value comparing after lengthening and followup means; ${ }^{\dagger} \mathrm{p}$ value comparing developmental method after lengthening using the preoperative and postoperative inhibition values; ${ }^{\$} \mathrm{p}$ value comparing developmental method at last followup using the preoperative and postoperative inhibition values; $\mathrm{CI}=$ confidence interval; $\mathrm{mLDFA}=$ mechanical lateral distal femoral angle; lat $=$ lateral deviation; med $=$ medial deviation . 
undertaken. The authors strive to attain at least $5 \mathrm{~cm}$ per lengthening surgery; however, if in any particular patient the lengthening was proceeding well with satisfactory knee motion and the child and family were tolerating it well and wished to continue, we would be willing to continue lengthening and even overlengthen to a total length obtained of $7.5 \mathrm{~cm}$ to decrease the amount of future lengthening needed.

\section{Results}

Length Achieved and ROM

The mean length achieved using this surgical method was $6 \mathrm{~cm}(\mathrm{SD} \pm 2$; range, $1.6-9 \mathrm{~cm})$ and the average time in the frame was 206 days $(\mathrm{SD} \pm 58$; range, $130-354$ days), yielding a healing index of 1.31 months $/ \mathrm{cm}(\mathrm{SD} \pm 1.1$; range, $0.5-6$ months $/ \mathrm{cm}$; Table 2). Accounting for growth of the normal femur, a net gain of $5 \mathrm{~cm}$ was achieved in the lengthened femurs ( $\mathrm{SD} \pm 1.9$; range, -0.5 to $9 \mathrm{~cm}$ ). The mean percent of femoral length discrepancy corrected was $115 \%$ ( $\mathrm{SD} \pm 52$; range, $15 \%-215 \%$ ) with greater than $100 \%$ indicating overlengthening of the femur resulting in a mean percent of overall limb length discrepancy corrected of $106 \%$ ( $\mathrm{SD} \pm 50$; range, $17 \%-200 \%)$. Of the 30 patients, $22(73 \%)$ reached the goal of equalizing femoral lengths.

The 12 patients ( $40 \%$ ) who underwent any previous surgery before their first femoral lengthening, excluding SUPERhip, SUPERknee, or combined SUPERhip and SUPERknee procedures, achieved less of the overall limb length difference than those patients who did not have other prior surgery $(68 \%$; range, $17 \%-157 \%$ versus $121 \%$; range, $33 \%-200 \%$; $\mathrm{p}=$ 0.009). Female patients achieved a greater average femur lengthening than males $(7 \mathrm{~cm}$; range, $4-9 \mathrm{~cm}$ versus $5 \mathrm{~cm}$; range, $1.6-7 \mathrm{~cm} ; \mathrm{p}=0.011)$; no other patient characteristics were associated with a difference in the amount of femoral length achieved with the numbers available.

Patient mean maximum knee flexion at the end of the lengthening portion of the treatment at a mean of 3.5 months after the index showed a decrease of $64^{\circ}$ (range, $15^{\circ}-90^{\circ}$ ) with recovery to normal flexion in almost all patients by 31.5 months (Table 3). Patient hip flexion showed a similar pattern with a decrease to $84^{\circ}$ (range, $25^{\circ}-100^{\circ}$ ) at the end of the lengthening portion of the treatment with a return to normal flexion by 31.5 months. Final measurement of hip ROM found no difference between preoperative and postoperative flexion or extension with the numbers available (hip flexion: mean difference of $-5^{\circ} \pm 20^{\circ} \mathrm{SD} ; 95 \% \mathrm{CI},=10 ; \mathrm{p}=0.219$; hip extension: mean difference of $-1^{\circ} \pm 5 \mathrm{SD} ; 95 \% \mathrm{CI}, 2 ; \mathrm{p}=$ $0.424)$. Final mean knee flexion decreased by only $7^{\circ}$ and extension decreased by $1^{\circ}$ with no difference between mean preoperative and postoperative measurements with the numbers available (knee flexion: mean difference of $-7^{\circ} \pm 29 \mathrm{SD} ; 95 \% \mathrm{CI}, 15 ; \mathrm{p}=0.467$; knee extension: mean difference of $-1^{\circ} \pm 9 \mathrm{SD} ; 95 \% \mathrm{CI}, 4 ; \mathrm{p}=0.757$ ). One patient had very limited knee ROM, from $10^{\circ}$ to $30^{\circ}$, and that patient underwent quadricepsplasty. Four patients had significantly limited knee flexion at the end of treatment, which were considered major complications, with maximum flexion of $30^{\circ}, 40^{\circ}, 65^{\circ}$, and $70^{\circ}$.

\section{Growth Inhibition and Predictive Length Calculations}

Mean preoperative inhibition was calculated to be $41 \%$ (range, $-38 \%$ to $300 \%$; $\mathrm{SD} \pm 72 ; 95 \% \mathrm{CI}, \pm 29 \%$ ), whereas mean postoperative inhibition was $16 \%$ (range, $-242 \%$ to $100 \%$; SD $\pm 61 \%$; $95 \% \mathrm{CI}, \pm 25 \%$ ), indicating a net stimulation of $25 \%(\mathrm{p}=0.055 ; \mathrm{SD} \pm 90 \%$; $95 \% \mathrm{CI}, \pm 36 \%$; Table 2). Patients with greater preoperative inhibition achieved a greater amount of length through distraction osteogenesis ( $\rho=0.435 ; p=0.03$ ). No difference was found when using the prelengthening growth inhibition compared with the postlengthening inhibition in predicting femoral length discrepancy at maturity with the developmental formula $(10.5 \pm 1.7 \mathrm{~cm}$; range, -3 to $77 ; \mathrm{CI}, \pm 7$ versus $6.5 \pm 6$ $\mathrm{cm}$; range, -9 to $15 ; \mathrm{CI}, \pm 2.5 ; \mathrm{p}=0.237$ ).

Table 3. Mean PODCI scores after femoral lengthening $(\mathrm{N}=23)$

\begin{tabular}{|c|c|c|c|c|}
\hline \multirow[t]{2}{*}{ PODCI category } & \multicolumn{2}{|c|}{ Standardized score } & \multicolumn{2}{|c|}{ Normative score } \\
\hline & Mean \pm SD & Range & Mean \pm SD & Range \\
\hline Upper extremity & $99 \pm 3$ & $88-100$ & $56 \pm 3$ & $46-57$ \\
\hline Basic mobility & $99 \pm 2$ & $93-100$ & $52 \pm 3$ & $41-53$ \\
\hline Sports and physical functioning & $89 \pm 11$ & $74-100$ & $46 \pm 11$ & $18-57$ \\
\hline Pain/comfort & $92 \pm 15$ & $44-100$ & $50 \pm 11$ & $15-55$ \\
\hline Happiness & $94 \pm 10$ & $55-100$ & $53 \pm 7$ & $25-57$ \\
\hline Global functioning & $95 \pm 6$ & $75-100$ & $51 \pm 8$ & $25-58$ \\
\hline
\end{tabular}

PODCI = Pediatrics Outcomes Data Collection Instrument. 


\section{Patient-reported Outcome Scores}

In all six PODCI categories surveyed, patients had favorable standardized and normative scores (Table 3), but patients who underwent femoral lengthening greater than 6 $\mathrm{cm}$ had both lower global functioning scores (90; SD \pm 10 versus 96; $\mathrm{SD} \pm 3 ; \mathrm{p}=0.043$ ) and worse pain/comfort scores (79; $\mathrm{SD} \pm 25$ versus 96; $\mathrm{SD} \pm 7 ; \mathrm{p}=0.029$ ), and patients who had mean percent femoral lengthening greater than $25 \%$ of initial femur length had worse pain/comfort scores (79; $\mathrm{SD} \pm 23$ versus 97; $\mathrm{SD} \pm 4 ; \mathrm{p}=0.012$ ) with similar global functioning scores $(90 ; \mathrm{SD} \pm 9$ versus 96 ; $\mathrm{SD} \pm 3 ; \mathrm{p}=0.058 ;$ Table 4).

\section{Complications}

The total number of complications was 30 in 60 planned surgical procedures (fixator application and removal). Ten of the $30(33 \%)$ complications were major, nine (30\%) were minor complications that required surgical intervention, and $11(37 \%)$ events were obstacles without residual effect on the patient (Table 5). One patient who lost $3 \mathrm{~cm}$ of length after external fixator removal subsequently required repeat femoral lengthening. One patient experienced three major complications and one event; another patient had one major complication, one minor complication, and two events. Half of the patients (15 of 30) experienced one or more obstacles or complications, and the other half had none. No differences in demographic, radiographic, or patient-based outcome measures were found between patients who had one or more events or complications compared with those patients who had no complications.

\section{Discussion}

Congenital femoral deficiency represents a rare, complex spectrum of osseous, muscular and ligamentous deformities and a standard surgical approach to its treatment is lacking. Correcting the femoral length discrepancy through lengthening poses a complex series of challenges and a variety of surgical techniques have been published in heterogeneous groups of patients with mixed results and complications. The goal of this study is to present objective radiographic and clinical data alongside patient-reported function using a validated outcomes measure in a well-

Table 5. Complications after lengthening surgery in congenital femoral deficiency $(\mathrm{N}=30)$

Events, $\mathrm{n}=11$

External fixator modification in OR; $n=4 *,+$

Botox injection into hamstrings in OR; $\mathrm{n}=3^{\dagger}$

Manipulation under anesthesia of the knee OR; $n=3$

Pin exchange in OR

Minor complications, $\mathrm{n}=9$

Tibia fracture requiring nonoperative treatment; $n=3$

Femoral regenerate fracture requiring prolonged external fixation time

Tibia fracture requiring ORIF

Tibia fracture requiring extension of fixation to distal tibia

Tibia fracture requiring IMN

Hip contracture requiring surgical release

Hip contracture requiring extension of fixation to pelvis ${ }^{\dagger}$

Major complications, $\mathrm{n}=10$

Loss of knee flexion (maximum flexion of $30^{\circ}, * 40^{\circ},{ }^{\dagger} 65^{\circ}$, and $70^{\circ}$ ); $\mathrm{n}=4$

Quadricepsplasty for limited knee flexion

Hip subluxation after frame removal requiring surgical release; $\mathrm{n}=2^{*}$

Osteomyelitis requiring IV antibiotics and débridement after frame removal*

Loss of $3 \mathrm{~cm}$ length after frame removal

Knee subluxation requiring PCL reconstruction

${ }^{\dagger}{ }^{\dagger}$ Each indicates one patient with multiple complications; OR = operating room; ORIF = open reduction and internal fixation; IMN = intramedullary nailing; IV = intravenous; $\mathrm{PCL}=$ posterior cruciate ligament.

Table 4. Global function and pain/comfort scores after femoral lengthening

\begin{tabular}{|c|c|c|c|c|c|c|c|c|c|}
\hline \multirow[t]{2}{*}{ Femoral lengthening } & & \multicolumn{4}{|l|}{ Global functioning score } & \multicolumn{4}{|l|}{ Pain/comfort score } \\
\hline & & Standardized normative & SD & Range & $\mathrm{p}$ value & Standardized normative & SD & Range & $\mathrm{p}$ value \\
\hline \multirow[t]{4}{*}{ Percent of initial femur length } & $\geq 25 \%$ & 90 & 9 & $75-100$ & & 79 & 23 & $44-100$ & \\
\hline & $\mathrm{n}=15$ & 45 & 13 & $25-58$ & & 40 & 17 & $15-56$ & \\
\hline & $<25 \%$ & 96 & 3 & $91-100$ & 0.058 & 97 & 4 & $89-100$ & 0.012 \\
\hline & $\mathrm{n}=8$ & 53 & 4 & $46-58$ & & 54 & 3 & $47-56$ & \\
\hline \multirow[t]{4}{*}{ Total length achieved } & $\geq 6 \mathrm{~cm}$ & 90 & 10 & $75-100$ & & 79 & 25 & $44-100$ & \\
\hline & $\mathrm{n}=16$ & 44 & 13 & $25-58$ & & 40 & 18 & $15-56$ & \\
\hline & $<6 \mathrm{~cm}$ & 96 & 3 & $91-100$ & 0.043 & 96 & 7 & $78-100$ & 0.029 \\
\hline & $\mathrm{n}=7$ & 53 & 4 & $46-58$ & & 52 & 5 & $40-56$ & \\
\hline
\end{tabular}


defined subset of patients who have undergone a consistent surgical technique. The current study shows that lengthening with an external fixator followed by intramedullary rodding achieves a mean lengthening of $6 \mathrm{~cm}$ with a lengthening index of 1.3 months $/ \mathrm{cm}$ while maintaining both hip and knee ROM, although 50\% of patients experienced complications during the prolonged surgical treatment. The surgical treatment regimen provides satisfactory patient-reported global functioning and pain control when the upper limit of lengthening is kept under $25 \%$ of the femoral length and does not cause growth inhibition of the lengthened limb in the subsequent 2 years.

Our study had a number of limitations. First, it was a small series of 32 patients; however, given that congenital femoral deficiency is a rare condition, it is on par with similar published series and all patients were treated with the same surgical technique. There is limited selection bias despite the small sample size because all patients who presented to the institution during the reviewed time period and met the inclusion criteria underwent the standardized surgical technique. Second, our study was a retrospective review and the possibility for transfer bias exists in that we are missing radiographic data on two of the 32 patients who underwent lengthening and patient-reported outcome measures on seven of the 30 patients with complete radiographic data. However, the missing radiographic data are a small number of patients and the seven patients whose PODCI outcomes measures were not collected were shown to be no different than the others. One strength of the study is that physical therapy was performed using the same modalities and techniques at the same institution and the data were measured and recorded by physical therapists rather than the treating surgeons. The radiographs were all performed at the same institution using the same techniques and magnification markers. Third, the rate of postoperative problems could not be collected accurately during a retrospective chart review; however, by definition, problems do not affect the outcome nor require surgical intervention. Fourth, the patient-based outcome measure was only collected at one time point rather than throughout treatment and, in some cases, was collected by mail. Fifth, our study is subject to assessor bias because two of the authors (SCS, DP) performed the surgeries; however, the radiographic measurements and chart review were performed by a surgeon (DEP) who did not perform the surgeries nor followup care of the patients.

The healing index of 1.3 months $/ \mathrm{cm}$ is quite favorable compared with published results of femoral lengthening for patients with congenital femoral deficiency. In older patients with Paley Type 1 congenital femoral deficiency, Aston et al. achieved mean femoral lengthening of $6 \mathrm{~cm}$ with a lower percent lengthening of $19 \%$ compared with the current study [4]. The healing index, postoperative knee flexion in distal osteotomies, complication rates, and amount of femoral length obtained were similar to those in our study, although the percent lengthening in the current

Table 6. Comparison of patient characteristics, surgical outcomes, and complications of current study with Aston et al

\begin{tabular}{|c|c|c|c|c|}
\hline \multicolumn{2}{|l|}{ Patient characteristics } & \multicolumn{2}{|c|}{ Aston et al. [4], $2009(\mathrm{~N}=30)$} & Current study $(\mathrm{N}=30)$ \\
\hline \multicolumn{2}{|l|}{ Femoral osteotomy site } & \multicolumn{2}{|l|}{$\begin{array}{l}17 \text { distal } \\
13 \text { proximal }\end{array}$} & 30 distal \\
\hline \multicolumn{2}{|l|}{ Age of patient (years; range) } & \multicolumn{2}{|l|}{$9(6-15)$} & $4.5(2-11)$ \\
\hline \multicolumn{2}{|c|}{ Congenital femoral deficiency, Paley type } & \multicolumn{2}{|l|}{ Type 1a } & Type $1 \mathrm{a}, 1 \mathrm{~b}, 2 \mathrm{a}$ \\
\hline \multicolumn{2}{|l|}{ Prior hip stabilization, number (\%) } & \multicolumn{2}{|l|}{$0(0)$} & $24(80)$ \\
\hline \multicolumn{5}{|l|}{ Surgical outcomes } \\
\hline \multicolumn{2}{|c|}{ Amount of femoral lengthening $(\mathrm{cm}$; range) } & \multicolumn{2}{|l|}{$6(3-10)$} & $6.1(1.6-9)$ \\
\hline \multicolumn{2}{|l|}{ Percent lengthening achieved (range) } & \multicolumn{2}{|l|}{$19(10-49)$} & $24(7-36)$ \\
\hline \multicolumn{2}{|l|}{ Healing index (days/cm; range) } & \multicolumn{2}{|l|}{$40(23-76)$} & $41(15-180)$ \\
\hline \multirow{2}{*}{\multicolumn{2}{|c|}{ Postoperative knee flexion (degrees) }} & Distal & Proximal & \\
\hline & & $124(70-140)$ & $98(15-140)$ & $128(30-160)$ \\
\hline Complications, number/Number (\%) & Total & Distal & Proximal & \\
\hline Femur fracture & $9 / 30(30)$ & $5 / 17(29)$ & $4 / 13(31)$ & $2 / 30(7)$ \\
\hline Quadricepsplasty & $7 / 30(23)$ & $6 / 17(35)$ & $1 / 13(8)$ & $1 / 30(3)$ \\
\hline \multicolumn{5}{|l|}{ Joint subluxation } \\
\hline \multicolumn{2}{|l|}{ Knee } & \multicolumn{2}{|l|}{$9 / 30(30)$} & $4 / 30(13)$ \\
\hline \multicolumn{2}{|l|}{ Hip } & \multicolumn{2}{|l|}{$1 / 30(3)$} & $2 / 30(7)$ \\
\hline \multicolumn{2}{|l|}{ Bone deformation } & \multicolumn{2}{|l|}{$6 / 30(20)$} & 6/30 (20) \\
\hline \multicolumn{2}{|l|}{ Deep infection } & \multicolumn{2}{|l|}{$0 / 30(0)$} & $1 / 30(3)$ \\
\hline
\end{tabular}


study was larger by achieving greater lengthening in smaller femurs (Table 6). Aston et al. incorporated the use of intramedullary fixation with nonlocked stainless steel rods at the index surgery and lengthened over the rods, whereas our technique prefers lengthening and then nailing with nonlocked stainless steel rods at the time of external fixation removal. The advantage of rodding after frame removal is that a longer and larger intramedullary nail can be placed, thus protecting the entire lengthened bone, including the half-pin sites, to prevent fracture and deformity through the regenerate. Our series also differed in that the surgery was performed in patients with more advanced types of congenital femoral deficiency, achieving similarly good results.

Patients in our study who underwent prelengthening surgical procedures, aside from the SUPERhip and SUPERknee procedures, achieved only $68 \%$ of the lengthening goal, which could have been the result of scarring, more severe osseous deformities, and muscle imbalances, but also resulting from having undergone the prior surgery at institutions with less experience in this rare condition. Because patients who underwent the SUPERhip and SUPERknee procedures before lengthening achieved $121 \%$ of their planned length suggests that these surgeries successfully stabilize the hip and knee for lengthening.

It is unclear to the authors why female patients were able to achieve significantly more length (more than $2 \mathrm{~cm}$ on average) compared with male patients. It is possible that the difference is the result of the neurodevelopmental stage of each gender at this age because girls may participate more in physical therapy and therefore are able to continue lengthening with less difficulty.

Overall, ROM data showed that despite a predictable decrease in ROM during lengthening, the vast majority of patients regained normal knee and hip ROM. These results from our study are similar to previously published results in a series of 25 patients who underwent isolated femoral lengthening of $6 \mathrm{~cm}$ on average, in which patient knee ROM decreased to a minimum of $37^{\circ}$ at the end of lengthening, increased to $69^{\circ}$ at the end of consolidation, and recovered to normal at last followup [16]. The authors estimate that the usual rate of improvement in ROM after lengthening is $10^{\circ}$ per month, but the last $20^{\circ}$ of knee flexion may take up to 2.5 years to recover. This is among the reasons that serial lengthenings are usually spaced apart by a minimum of 3 years.

Popkov et al. published a comprehensive report on factors that influence postoperative growth after limb lengthening using the Ilizarov technique in 86 children (59 femoral and 55 tibial lengthenings) with a mean bone age of 8.5 years at first lengthening for various congenital conditions [34]. The mean femoral lengthening was $5 \mathrm{~cm}$ for a mean percent lengthening of $20 \%$ and average followup was 4.5 years after fixator removal. Initiation of lengthening before age 12 years in boys and age 9 years in girls was associated with long-term stimulation, whereas surgical intervention after the onset of puberty resulted in inhibition. Serial lengthening within 3 years severely impaired residual growth in both the femur and tibia, and percentage lengthening greater than $30 \%$ showed a temporary reduction in growth that resolved by the end of the first year after lengthening surgery. The stimulatory effect when lengthening was performed under optimal conditions was found to reach up to $5 \%$ of the final lengthened segment. Some authors have found no change in growth rate in older patients [17, 21, 24, 46], although some authors have found stimulatory effects in young patients despite a higher mean percent lengthening [38]. In our study, using preoperative and postoperative measurements of developmental femoral and overall length discrepancies matched the findings of Popkov et al. and others, showing no detrimental effect on femoral growth in young patients who underwent a relative femoral lengthening greater than $23.5 \%$ [17, 21, 45]. However, our study could not support the hypothesis that femoral lengthening stimulates growth as has been previously postulated $[34,38]$. One explanation is that at only 2 years after lengthening, patients who had undergone higher percentage lengthening may still be recovering their growth rate. Longer followup may elucidate the stimulatory effect of lengthening at a young age.

Oostenbroek et al. extended the external fixator across to the tibia with a knee hinge in their group of patients who underwent lengthening procedures for congenital and traumatic conditions, postulating that bridging across the knee has an additional benefit of inducing growth stimulation; however, this was not seen in the large series of congenital cases reported by Popkov et al. [26, 34]. The low rate of knee subluxation or dislocation in this study, without a detrimental effect on growth, supports the strategy of bridging the external fixator across the knee to maintain stability and ROM during lengthening. Theoretically, the distal femur and proximal tibia are growing during the several months that these physes are confined by the knee spanning external fixator. Normal distal femurs may grow up to $4.5 \mathrm{~mm}$ in 6 months and normal proximal tibias up to $3 \mathrm{~mm}$ in 6 months; however, there is a growth inhibition in the physes of the femurs and tibias of patients with congenital femoral deficiency. This study did not measure the growth specifically of the distal femur and proximal tibia independently during the lengthening period and cannot specifically show that the spanning external fixator does cause inhibition of the distal femur or proximal tibia physes. However, given that these two physes account for the majority of growth of the leg, it is likely that the growth stimulation observed occurs in these physes, but causality to the knee hinge cannot be implicated [26]. 
Furthermore, more recent external fixator designs, including the LRS fixator used in this study, can be configured to allow either distraction or sliding expansion across the knee hinge.

The patient-based PODCI scores illustrate that overall patients had good function at intermediate followup comparable with that of same-aged children without congenital femoral deficiency. This is potentially the most important finding of our study because it is a direct measure of outcome from the patient's perspective, although this measure should be continuously evaluated beyond childhood and adolescence into adulthood and after all corrective surgeries are completed because patients with more severe congenital femoral deficiency often require additional lengthening to equalize leg lengths. The PODCI scores do, however, caution against excessive lengthening beyond 6 $\mathrm{cm}$ or $25 \%$ relative femoral lengthening to maintain higher function and less pain after lengthening.

The proportion of obstacles, minor complications, and major complications after surgery for congenital femoral lengthening reported in our study is within the range of published reports $(46 \%-130 \%)$ [22, 26, 27]. We found proportions of $50 \%$ complications per surgery, $53 \%$ complication per patient, and $97 \%$ complication per bone lengthened. Recently, Oostenbroek et al. reported a complication rate of $69 \%$ per lengthened bone and showed that limb length discrepancy is the only predictor for complications after surgery [26]. The proportion of fractures in our study was $16.7 \%$ (five of 30) per lengthened segments compared with published rates of $8 \%$ to $50 \%$, and the proportion of hip and knee contracture/stiffness was $30 \%$ (nine of 30) per lengthened segments compared with published rates of $10 \%$ to $85 \%$ [4, 9, 19, 26, 35, 36, 39]. Other postoperative obstacles and complications found in our series occurred within published ranges: modifications of the external fixator in the operating room (13.3\%); Botox injections into the hamstrings and manipulations under anesthesia (10\%); osteomyelitis (3\%); loss of regenerate length (3\%); quadricepsplasty (3\%); and pin exchange in the operating room (3\%). Taken together the high frequency of obstacles and complications and the lower femoral lengthening achieved in patients who underwent previous surgery, the authors believe that these patients are best treated in tertiary referral centers focusing on patients with congenital femoral deficiency.

Our study results support the described surgical technique for femoral lengthening in patients with mild and moderate congenital femoral deficiency as successful and well tolerated by patients. Study results support the individual aspects of the surgical technique as well, including performing distraction osteogenesis at younger ages, between ages 3 and 5 years, a maximum percent lengthening of $25 \%$, which correlates with $6 \mathrm{~cm}$ of absolute length, bridging the knee with an articulated external fixator, intensive physical therapy, insertion of an intramedullary rod on frame removal, and prompt identification and treatment of postlengthening problems and obstacles. The study showed positive patient-measured outcome scores, indicating a good to excellent quality of life after undergoing lengthening. Additional studies are needed to follow long-term patient-reported outcome measures, especially after a second or third lengthening and the long-term effect of lengthening on the rate of growth of the leg. Our results also caution against lengthening beyond $25 \%$ of the femoral length to assure a good outcome, especially with regard to patient pain and function.

\section{References}

1. Ackman J, Altiok H, Flanagan A, Peer M, Graf A, Krzak J, Hassani S, Eastwood D, Harris GF. Long-term follow-up of Van Nes rotationplasty in patients with congenital proximal focal femoral deficiency. Bone Joint J. 2013;95:192-198.

2. Aitken GT. Proximal femoral focal deficiency-definition, classification, and management. In: Aitken GT, ed. Proximal Femoral Focal Deficiency. A Congenital Anomaly. Washington, DC, USA: National Academy of Sciences; 1969:1-22.

3. Amstutz HC, Wilson PD. Dysgenesis of the proximal femur (coxa vara) and its surgical management. J Bone Joint Surg Am. 1962;44:1-24

4. Aston WJS, Calder PR, Baker D, Hartley J, Hill RA. Lengthening of the congenital short femur using the Ilizarov technique: a single-surgeon series. J Bone Joint Surg Br. 2009;91:962-967.

5. Clement DA, Colton CL. Overgrowth of the femur after fracture in childhood. An increased effect in boys. J Bone Joint Surg Br. 1986;68:534-536.

6. Daltroy LH, Liang MH, Fossel AH, Goldberg MJ. The POSNA pediatric musculoskeletal functional health questionnaire: report on reliability, validity, and sensitivity to change. Pediatric Outcomes Instrument Development Group. Pediatric Orthopaedic Society of North America. J Pediatr Orthop. 1998;18:561-571.

7. Edvardsen P, Syversen SM. Overgrowth of the femur after fracture of the shaft in childhood. J Bone Joint Surg Br. 1976;58:339-342.

8. Gillespie R, Torode IP. Classification and management of congenital abnormalities of the femur. $J$ Bone Joint Surg Br. 1983;65:557-568.

9. Grill F, Dungl P. Lengthening for congenital short femur. Results of different methods. J Bone Joint Surg Br. 1991;73:439-447.

10. Hamanishi C. Congenital short femur. Clinical, genetic and epidemiological comparison of the naturally occurring condition with that caused by thalidomide. J Bone Joint Surg Br. 1980;62:307-320.

11. Hamel J, Winkelmann W, Becker W. A new modification of rotationplasty in a patient with proximal femoral focal deficiency Pappas type II. J Pediatr Orthop B. 1999;8:200-202.

12. Hariga H, Mousny M, Docquier PL. Leg length discrepancy following femoral shaft fracture in children: clinical considerations and recommendations. Acta Orthop Belg. 2011;77:782-787.

13. Harris JD, Trinh TQ, Scharschmidt TJ, Mayerson JL. Exceptional functional recovery and return to high-impact sports after Van Nes rotationplasty. Orthopedics. 2013;36:e126-131.

14. Haynes RJ, Sullivan E. The Pediatric Orthopaedic Society of North America Pediatric Orthopaedic Functional Health 
Questionnaire: an analysis of normals. $J$ Pediatr Orthop. 2001;21:619-621.

15. Herring JA, Birch JG. Congenital femoral deficiency. In: Herring JA, Birch JG, eds. The Child With a Limb Deficiency. Rosemont, IL, USA: American Academy of Orthopaedic Surgeons; 1998: 61-150.

16. Herzenberg JE, Scheufele LL, Paley D, Bechtel R, Tepper S. Knee range of motion in isolated femoral lengthening. Clin Orthop Relat Res. 1994;301:49-54.

17. Hope PG, Crawfurd EJ, Catterall A. Bone growth following lengthening for congenital shortening of the lower limb. J Pediatr Orthop. 1994;14:339-342.

18. Hougaard K. Femoral shaft fractures in children: a prospective study of the overgrowth phenomenon. Injury. 1989;20:170-172.

19. Koman LA, Meyer LC, Warren FH. Proximal femoral focal deficiency: a 50-year experience. Dev Med Child Neurol. 1982;24:344-355.

20. Kostuik JP, Gillespie R, Hall JE, Hubbard S. Van Nes rotational osteotomy for treatment of proximal femoral focal deficiency and congenital short femur. J Bone Joint Surg Am. 1975;57:1039-1046.

21. McCarthy JJ, Kim H, Saluan P, Karsky D, Davidson RS. The effects of limb lengthening on growth. J Pediatr Orthop B. 2003;12:328.

22. Nogueira MP, Paley D, Bhave A, Herbert A, Nocente C, Herzenberg JE. Nerve lesions associated with limb-lengthening. $J$ Bone Joint Surg Am. 2003;85:1502-1510.

23. Nordin S, Ros MD, Faisham WI. Clinical measurement of longitudinal femoral overgrowth following fracture in children. Singapore Med J. 2001;42:563-565.

24. Oostenbroek HJ, Brand R, van Roermund PM. Growth rate after limb deformity correction by the Ilizarov method with or without knee joint distraction. Acta Orthop. 2009;80:338-343.

25. Oostenbroek HJ, Brand R, van Roermund PM. Lower limb deformity due to failed trauma treatment corrected with the Ilizarov technique. Acta Orthop. 2009;80:435-439.

26. Oostenbroek HJ, Brand R, van Roermund PM, Castelein RM. Paediatric lower limb deformity correction using the Ilizarov technique: a statistical analysis of factors affecting the complication rate. J Pediatr Orthop B. 2014;23:26-31.

27. Paley D. Problems, obstacles, and complications of limb lengthening by the Ilizarov technique. Clin Orthop Relat Res. 1990;250:81-104.

28. Paley D. Principles of Deformity Correction. 1st ed. New York, NY, USA: Springer; 2003:1-821.

29. Paley D, Bhave A, Herzenberg JE, Bowen JR. Multiplier method for predicting limb-length discrepancy. J Bone Joint Surg Am. 2000;82:1432-1446.

30. Paley D, Herzenberg JE, Tetsworth K, McKie J, Bhave A. Deformity planning for frontal and sagittal plane corrective osteotomies. Orthop Clin North Am. 1994;25:425-465.
31. Paley D, Standard SC. Lengthening reconstruction surgery: for congenital femoral deficiency. In: Rozbruch SR, Ilizarov S, eds. Limb Lengthening and Reconstruction Surgery. Boca Raton, FL, USA: CRC Press; 2006:393-428.

32. Paley D, Tetsworth K. Mechanical axis deviation of the lower limbs. Preoperative planning of uniapical angular deformities of the tibia or femur. Clin Orthop Relat Res. 1992;280:48-64.

33. Paley D, Tetsworth K. Mechanical axis deviation of the lower limbs. Preoperative planning of multiapical frontal plane angular and bowing deformities of the femur and tibia. Clin Orthop Relat Res. 1992;280:65-71.

34. Popkov D, Journeau P, Popkov A, Pedeutour B, Haumont T, Lascombes P. Analysis of segmental residual growth after progressive bone lengthening in congenital lower limb deformity. Orthop Traumatol Surg Res. 2012;98:621-628.

35. Radler C, Antonietti G, Ganger R, Grill F. Recurrence of axial malalignment after surgical correction in congenital femoral deficiency and fibular hemimelia. Int Orthop. 2011;35:1683-1688.

36. Ramseier LE, Exner GU. [Lengthening of proximal femoral focal deficiency using a hybrid fixation with inclusion of the knee joint] [in German]. Orthopade. 2007;36:582-587.

37. Reynolds DA. Growth changes in fractured long-bones: a study of 126 children. J Bone Joint Surg Br. 1981;63:83-88.

38. Sabharwal S, Paley D, Bhave A, Herzenberg JE. Growth patterns after lengthening of congenitally short lower limbs in young children. J Pediatr Orthop. 2000;20:137-145.

39. Shabtai L, Specht SC, Standard SC, Herzenberg JE. Internal lengthening device for congenital femoral deficiency and fibular hemimelia. Clin Orthop Relat Res. 2014;472:3860-3868.

40. Shapiro F. Fractures of the femoral shaft in children. The overgrowth phenomenon. Acta Orthop. 1981;52:649-655.

41. Simpson-White RW, Fernandes JA, Bell MJ. King's procedure for Aitken B/Paley 2a proximal femoral focal deficiency with 19year follow-up-a case report. Acta Orthop. 2013;84:323-325.

42. Stephens MM, Hsu LC, Leong JC. Leg length discrepancy after femoral shaft fractures in children. Review after skeletal maturity. J Bone Joint Surg Br. 1989;71:615-618.

43. Torode IP, Gillespie R. The classification and treatment of proximal femoral deficiencies. Prosthet Orthot Int. 1991;15: $117-126$.

44. Van Nes CP. Methods of treating pseudoarthrosis of the femoral neck, and their indications. Arch Chir Neerl. 1959:11:327-342.

45. Viehweger E, Pouliquen J-C, Kassis B, Glorion C, Langlais J. Bone growth after lengthening of the lower limb in children. J Pediatr Orthop B. 1998;7:154-157.

46. Westberry DE, Davids JR. Proximal focal femoral deficiency (PFFD): management options and controversies. Hip Int. 2009; 19(Suppl 6):S18-25. 